\title{
Memorial acadêmico para Professor Titular
}

\author{
Exercício de escrita de si: uma trajetória \\ intelectual no âmbito do ensino e da \\ pesquisa em história da educação ${ }^{1}$
}

\author{
Carlos Eduardo Vieira²
}

\section{Introdução}

Os memoriais têm longa tradição acadêmica no Brasil, constituem-se em documentos que expõem trajetórias de professores universitários para fins de concursos ou de progressões ao longo das suas carreiras. No caso específico das universidades federais e da progressão para a classe de Professor Titular a ampliação do acesso a esse nível da carreira é a resultante de uma greve do movimento docente. Entre as concessões ao Estado e as conquistas da categoria, essa greve garantiu que todos os professores que alcançarem o nível de Professor Associado 4 possam pleitear essa ascensão. Nas regras anteriores de distribuição de vagas para Professor Titular, a possibilidade dessa promoção era muito reduzida, envolvia a perda de direitos trabalhistas, além de produzir uma competição intensa entre pares do mesmo departamento.

Para além dessa função de avaliação institucional, os memoriais apresentam o potencial de testemunho da experiência universitária dos professores, considerando as ações de ensino, pesquisa e extensão. Muitos desses documentos são publicados pelos seus autores, seja nas bases de dados das próprias universi-

DOI: $10.1590 / 0104-4060.49878$

1 Este texto foi apresentado, originalmente, como Memorial Acadêmico para progressão de Carlos Eduardo Vieira para a categoria de Professor Titular, da Disciplina de História da Educação, no Departamento de Teoria e Fundamentos da Educação, da Universidade Federal do Paraná, no dia 30 de novembro de 2016. Compuseram a banca examinadora como membros titulares: Dr. Luciano Mendes de Faria Filho (UFMG); Dr. Marcus Levy Albino Bencostta (UFPR); Dra. Maria Elisabeth Blanck Miguel (PUC-PR); e Dra. Mirian Jorge Warde (UniFesp).

2 Universidade Federal do Paraná. Curitiba, Paraná, Brasil. Setor de Educação. Rua General Carneiro, nº 460. Centro. CEP: 80060-150.E-mail: cevieira9@gmail.com 
dades, em livros ou nas seções de documentos de algumas revistas acadêmicas, como é o caso da Educar em Revista, do Setor de Educação da UFPR. O sociólogo Paulo Miceli, por exemplo, incluiu o seu memorial de Professor Titular na USP na obra que reúne as suas principais contribuições para a sociologia e a história dos intelectuais no Brasil, intitulada Intelectuais à Brasileira, de 2001.

A publicidade desses documentos, associada ao seu potencial como fonte para a análise da história institucional e/ou das histórias de vida de professores universitários, tem motivado alguns pesquisadores a desenvolverem estudos, tomando esses escritos autobiográficos como fontes. Como exemplo desse tipo de iniciativa poderíamos citar o artigo Trajetória intelectual de pesquisadores da educação: a fecundidade do estudo dos memoriais acadêmicos, de Teresa Cristina Rego.

No texto a autora afirma que

[...] os memoriais permitiram conhecer o ponto de vista crítico e metateórico do pesquisador ao analisar seu próprio percurso de formação e produção acadêmica ao longo dos anos dedicados à atuação ou pesquisa na área da educação, explicitando aspectos que a leitura direta de textos dispersos dos pensadores nem sempre revela. (REGO, 2014, p. 783).

Os memoriais são escritos na primeira pessoa do singular, da mesma forma que as cartas, as confissões, os diários e as memórias. Esse gênero de escrita de si expõe as razões do sujeito na sua parcialidade e subjetividade. Trata-se de um gênero que produz um certo grau de desconforto entre os pesquisadores acadêmicos, uma vez que, por razões de ofício, esses aprenderam a escrever na terceira pessoa do singular ou na primeira pessoa do plural, na pretensão de produzir os efeitos de imparcialidade e impessoalidade.

Para além da falta de prática no uso da primeira pessoa do singular, nos deparamos com uma série de dificuldades ainda maiores. Como especialistas em história fomos treinados para desmontar as mitologias presentes nas hagiografias e memórias dos personagens que analisamos, a partir do que Pierre Bourdieu (2006) chamou de ilusão biográfica. Escritas ilusórias porque impõem uma racionalização arbitrária ao vivido, de modo a produzir um ser uno, coerente e movido, de maneira inabalável, por um propósito de vida.

Se no gênero biográfico identificamos as ilusões dos escritores em relação aos seus personagens ou, nos termos propostos por François Dosse (2009), a possessão do biógrafo pelo biografado, no gênero autobiográfico esse tipo de problema se torna ainda mais complexo, uma vez que a busca pelo sentido da 
vida deixa de ser uma questão de identificação e transferência entre autor e personagem, como o mesmo Dosse alerta, para se tornar um dilema ontológico, associado à necessidade existencial do sujeito de se autorrepresentar como unidade de sentido, pleno de coerência e propósito.

As obras de Marcel Proust, James Joyce, Fiódor Dostoiévski e/ou Machado de Assis demoliram a ideia de coerência do sujeito, demonstrando a convivência ora pacífica, ora contraditória, de identidades múltiplas, de sujeitos fragmentados. Essas características humanas são marcantes em personagens como Raskólnikov, de Crime e Castigo, ou Bentinho, de Dom Casmurro, dilacerados pelas suas contradições, incoerências e inconsistências entre os seus princípios morais e práticas sociais. Esse sujeito cambiante vai ao paroxismo em Memórias Póstumas de Brás Cubas, já que há um tempo o sujeito está morto, mas narra a sua vida. Na historiografia contemporânea, os princípios do descentramento e da fragmentação do sujeito, adotado em grande medida pela literatura, foram absorvidos para a análise dos personagens históricos. Não obstante, a aceitação teórica dessas premissas não facilita a escrita de si, de modo que representar as próprias incertezas, contradições e incoerências não é tarefa das mais gratificantes.

Alguns autores enfrentaram esse desafio de autoanálise, inclusive o já mencionado Bourdieu, no seu Esboço de Autoanálise, e o filósofo Louis Althusser, no seu $A$ história dura muito tempo. Esse último incluiu na produção da sua autobiografia um problema a mais, ao introduzir a categoria inconsciente na análise. Esse tipo de problematização psicanalítica mostra que mesmo que estejamos vigilantes para evitar a racionalização do passado, à luz da realidade pensada e vivida no presente, os mitos autorrepresentacionais seguem como possibilidade e, pior, em grande medida inacessíveis à consciência. Nessa chave de leitura, ninguém poderá ter plena segurança de quem é, das razões das suas decisões ou do propósito da sua vida. No máximo, se conduzidos por um/uma competente psicanalista, podemos formular hipóteses sobre quem somos, com um risco enorme de nos decepcionarmos profundamente, pois ao contrário de metas racionais e dos princípios éticos firmes, podemos encontrar, interpretando nossos atos falhos, sonhos e não ditos, sentimentos primitivos difíceis de serem expostos publicamente.

Logo, sem qualquer pretensão de conclusão inovadora, podemos afirmar que não existem biografias ou autobiografias que narrem a verdade e a totalidade do vivido e muito menos daquilo que foi sentido, já que não existe um significado unívoco para uma vida. Nos restam apenas exercícios de análise e de autoanálise que captam alguns momentos significativos, escolhidos e modelados pela lógica do sujeito da narrativa, que podem vir a ser parte da memória, ou 
seja, parte de um conhecimento social que, segundo Paul Ricoeur (2007), está marcado profundamente pelo esquecimento, pela distorção e pela seletividade.

Esta introdução ensaística e superficial sobre a escrita de si não tem como ambição dizer algo que não seja plenamente conhecido pelos especialistas na escrita biográfica e histórica. A rigor, são premissas orientadoras da escrita que repetidas como mantras, auxiliam o autor deste memorial a começar a narrativa, aplicando a primeira pessoa do singular e, talvez, evitando ingenuidades e armadilhas na produção da sua autobiografia intelectual. Quiçá as questões apresentadas acima contribuam na atenuação do meu melindre no exercício da escrita de si. Porém, o desconforto segue e é incontornável, já que este texto me expõe, ainda que consciente ou inconscientemente, muitas coisas serão omitidas ou reelaboradas racionalmente, evitando o que eu considere pouco louvável na minha carreira. Outro aspecto desalentador neste exercício de ego história é a sensação de parecer arrogante, na medida em que escrevemos em primeira pessoa enfatizando nossos feitos e desfeitos. Contudo, não tenho como contornar esse exercício autobiográfico, pois o desejo do título de Professor Titular excede meu recato.

Tanto por aspectos políticos quanto pragmáticos vejo como uma distinção poder me tornar Professor Titular, tendo em vista que com essa posição angario mais poder nos enfrentamentos do dia a dia nas trincheiras acadêmicas, além de melhorar os meus rendimentos. Vejo também o sentido, evidentemente ilusório, de completar uma carreira, uma vez que ingressei na UFPR como Professor Auxiliar e hoje tenho a possibilidade de conquistar o acesso à classe dos titulares. Na minha autoavaliação é justo que eu receba essa promoção como coroamento de vinte e quatro (24) anos de trabalho na UFPR. Contudo, essa ideia de justiça e essa noção aristocrática de coroamento soam como indícios de argumentos autolegitimadores da minha própria trajetória. De toda a forma, à banca cabem os julgamentos. De minha parte me proponho a apresentar uma autobiografia intelectual, uma vez que a pessoal, por interdito natural, eu jamais alcançaria torná-la pública.

Apoiado nas premissas acima discutidas antecipo, então, que a narrativa não obedecerá uma lógica cronológica, ao contrário, será lacunar e, sobretudo, não terá a pretensão de produzir um efeito de compatibilização entre o vivido e o pensado. Sigo, em síntese, as recomendações de Sabina Loriga (1998), de maneira a pensar a minha trajetória a partir da metáfora do coral.

A imagem desse animal marinho metaforiza a história de vida como uma multiplicidade de experiências justapostas, sem um centro organizador ou irradiador e sem um propósito unívoco. Dessa forma, pretendo narrar alguns aspectos da minha trajetória como professor na UFPR e em outros espaços sociais e acadêmicos em que circulei e convivi, formando as múltiplas identidades que me definem. 


\section{Do ingresso: entre reveses e reinvenções}

Como aluno mediano no ensino primário e ginasial fui sempre socorrido nas tarefas escolares pelas minhas quatro irmãs, dedicadas às suas próprias obrigações e ao irmão caçula. Mãe professora primária, atenta aos filhos, mas ocupada a ponto de proporcionar liberdade a todos. Pai também professor, no nível secundário, da disciplina de História. Casa repleta de livros e regularmente afeita a discussões dos problemas suscitados pela literatura, pela história e, sobretudo, pela política. Nesse ambiente, formei um habitus que me predispôs a determinadas práticas, entre as quais o apreço pela leitura que, ao contrário das minhas irmãs, só foi se firmar realmente lá pelos quinze (15) anos. Antes disso, entendia que existiam coisas mais importantes a fazer: jogar futebol, nadar no clube e aprender coisas sobre a vida das meninas e dos meninos. $\mathrm{O}$ gênero privilegiado para a leitura nos anos da adolescência foi a literatura, a partir dos livros de suspense e mistério de Arthur Conan Doyle. O habitus se fortaleceu e, entre os vinte (20) e trinta (30) anos, somaram-se muitos autores dos chamados clássicos: Homero, Sófocles, Shakespeare, Dante, Kafka, Fernando Pessoa, Saramago, Dostoiévski, Machado de Assis e Miguel de Cervantes. Contudo, escritores não tão célebres fizeram parte das minhas preferências, particularmente aqueles que descreviam cenários que retratavam questões sociais e políticas, destacando-se como exemplos o livro $A$ Mãe, de Máximo Gorki, que trata da vida cotidiana de uma mulher no contexto da Revolução Russa, e $O$ Zero $e$ $o$ Infinito, de Arthur Koestler, inspirado na prisão e na aniquilação de líderes bolcheviques pelo stalinismo.

Da literatura para a teoria política foi um passo, já que o debate em torno da política marcava o meu ambiente familiar. José Vieira Neto, irmão mais velho de meu pai, foi o primeiro Deputado do Partido Comunista Brasileiro (PCB) eleito no Paraná, em 1946. O meu contato com este tio não envolveu a discussão política, pois quando ele faleceu eu ainda era uma criança, contudo, o espectro do comunismo continuou rondando a família.

Refiro-me a essas memórias e a esse ambiente familiar porque o meu interesse pelo estudo da sociedade e do indivíduo não foi consequência do ambiente escolar, na verdade não gostava de ir para escola. Foi no convívio familiar que despertei para pensar problemas sociais e políticos, em particular para refletir sobre o contexto da ditadura militar que marcou a minha geração. Geração Coca-Cola, nascida na década de 1960, na expressão do músico e poeta Renato Russo, meu contemporâneo. Logo, as leituras de Lenin, Marx e Trotsky passaram a fazer parte do meu espaço de experiência e, particularmente, 
do meu horizonte de expectativas, para mencionar os conceitos elaborados por Reinhart Koselleck, uma vez quer essas leituras faziam parte de um telos em que a revolução socialista no Brasil seria o ponto de chegada e um novo ponto de partida. A filiação ao clandestino Partido Comunista Brasileiro (PCB), no início dos anos de 1980, foi uma consequência desse processo, revelando um traço de personalidade que somente agora posso de fato compreender: a moderação política. Pode parecer estranho falar em moderação quando pensamos em adesão ao comunismo e à ideia de revolução, contudo, no contexto da militância dos jovens de esquerda da minha geração, o partidão era tido como revisionista e reformista, já que não pregava a luta armada contra o regime militar e defendia a organização da sociedade civil para a reconquista da democracia.

Concomitante à formação literária e à militância política, desenvolvi um gosto que, felizmente, ainda me acompanha: o esporte. Primeiro o futebol na rua com a piazada, depois a natação, o handebol, que me levou a representar o Brasil em vários torneios no exterior, e, no momento atual, o tênis, praticado religiosamente, pelo menos cinco vezes por semana. O interesse pelo esporte superou o interesse literário e o estudo do marxismo na minha primeira escolha de formação superior, uma vez que foi no curso de Educação Física que realizei o meu primeiro contato com a universidade e com as questões associadas à educação brasileira.

Não obstante, a formação obtida na universidade não supria meus interesses de aprofundamento nos estudos filosóficos e políticos, sendo assim, em 1987, ingressei em uma pós-graduação lato sensu em Filosofia da Educação, na PUC do Paraná. Nesse espaço conheci Antônio Joaquim Severino, professor atuante na filosofia da educação e, na época, associado ao Programa de Pós-Graduação stricto sensu da PUC-SP. Creio que o meu bom desempenho na sua disciplina levou-o a me incentivar a tentar o mestrado na PUC-SP. Entre os meus colegas de curso Marcus Aurélio Taborda de Oliveira, irmão que admiro e que me acompanhava no PCB e me acompanha na carreira acadêmica. Ainda neste curso, além do Severino, computo o contato com a professora Anita Helena Schlesener, na época do Departamento de Filosofia da UFPR e especialista em Gramsci. Com ela troquei as minhas primeiras impressões sobre o pensamento gramsciano, que já conhecia por conta das leituras no interior do PCB, ainda que Gramsci não fosse parte do cânone dos teóricos marxistas preferidos pelo PCB. A suspeição sobre Gramsci no partido era decorrente da crença sobre a sua influência na formação do chamado eurocomunismo, movimento liderado principalmente pelo Partido Comunista Italiano e que destoava da orientação soviética no interior do movimento comunista internacional.

O curso de pós-graduação em filosofia da educação produziu consequências: a decisão de prestar novo vestibular e ingressar no curso de graduação 
em Filosofia, na PUC-PR; a retomada do contado com as discussões sobre a educação e a pesquisa educacional; e o estudo de alguns textos de Gramsci fora do ambiente da militância.

Todavia, os novos estudos graduados e pós-graduados em filosofia não significavam interesse de enraizamento acadêmico, uma vez que a política seguia como o meu propósito principal. Nessas alturas dos meus saudosos vinte e cinco (25) anos acreditei que seria um quadro profissional do partido, dedicando todas as minhas energias a esse projeto que envolvia princípios ideológicos e prazer em viver o jogo do poder. Como Presidente da Juventude Comunista do Paraná me movimentava bem entre os jovens e os velhos comunistas, já que esses me viam como herdeiro do Deputado Comunista Vieira Neto, meu tio e mito dentro do partidão no Paraná. A partir de 1985, com o PCB experimentando uma nova fase de legalidade institucional, ascendi a posições de mando na estrutura do partido ainda muito jovem, tanto no âmbito municipal, como estadual.

O ponto decisivo dessa jornada foi quando assumi a coordenação da campanha do partido em Curitiba nas eleições de 1988, na qual apoiávamos a candidatura de Maurício Fruet do PMDB para prefeito. Esse contava também com o apoio do Prefeito Roberto Requião e do Governador do Estado Álvaro Dias, ambos do PMDB. Nesse pleito tínhamos como certa a eleição de Fruet e, por extensão, de um vereador do PCB em Curitiba. A eleição deles me levaria, de acordo com os meus planos ideológicos e laborais, à chefia do gabinete do vereador na Câmara Municipal. Talvez estivesse calculando mal, já que essa seria uma função estratégica para o partido e, por extensão, muito concorrida, mas, quem sabe, uma assessoria fosse possível.

Contudo, os planos de levar o PCB à Câmara Municipal e, principalmente, os de me empregar na política foram por água abaixo em função do ingresso inusitado de Jaime Lerner para concorrer nesse pleito, quando faltavam apenas 12 dias para a eleição. Fruet não se elegeu e o PCB somou ínfimos votos. A rigor, mesmo que Fruet fosse eleito é bem provável que o PCB, consoante ao conservadorismo do eleitor Curitibano, não elegesse um vereador. À época, nós, os militantes, acreditávamos que se o comunismo prosperasse no Brasil, a República de Curitiba seria o equivalente a ilha de Formosa (Taiwan), ou seja, o lugar em que os anticomunistas se refugiaram e estabeleceram seus domínios, depois da vitória do Partido Comunista na China continental.

O insucesso na eleição ainda rendeu o meu afastamento e de muitos dos meus camaradas da direção do partido na capital, já que alguma cabeça deveria expiar o desastre eleitoral. Nesse cenário, sem emprego fixo e sem perspectivas viáveis de profissionalização na política, assim como João de Santo Cristo, da letra do Faroeste Caboclo, de Renato Russo, elaborei “mais uma vez [o meu] 
plano santo para a vida começar". Entre as possibilidades, considerei a ideia que fora sugerida a mim alguns anos antes: fazer mestrado na PUC-SP.

A tentativa de ingresso na PUC-SP foi realizada no segundo semestre de 1989. No dia da entrevista encontrei, no corredor da instituição, o incentivador da minha ida à PUC-SP, professor Severino. Cumprimentamo-nos e então disse a ele que estava ali porque faria a entrevista, já que fora aprovado na prova escrita, visando o ingresso no mestrado. Este saudou-me pelo feito e me disse que não era mais professor do programa, uma vez que a Universidade de São Paulo, seu outro vínculo institucional, exigiu dele a dedicação exclusiva. Me despedi e passei a me conformar que o orientador idealizado não seria possível. A rigor, nada seria possível para mim naquele momento na PUC-SP, vez que acabei reprovado na entrevista.

Seguindo no estudo da filosofia me preparei melhor para o ingresso no mestrado no começo de 1990, contudo, ampliei minhas opções. Tentaria mais uma vez na PUC-SP, mas incluiria o programa de mestrado em educação da UFPR entre as opções. O exame na UFPR aconteceu antes da seleção da PUC-SP $\mathrm{e}$, aprovado na prova escrita, novamente fui reprovado na entrevista. Sem muitas esperanças de sucesso, voltei à PUC-SP alguns meses depois e selecionado para a entrevista, agora com uma nova examinadora, professora Mirian Jorge Warde, levei minhas ideias desajeitadas e toscas sobre Gramsci e, para minha surpresa, passei e segui na PUC-SP por quase oito (8) anos.

Defendida a dissertação, ingressei no doutorado, seguindo com a Mirian Warde e com o Gramsci. É evidente que esse não foi um caminho sem tensões, mas foi determinante para a minha formação como pesquisador e membro da academia. Hoje consigo dimensionar como foi importante ter reprovado no exame para o mestrado na UFPR, pois caso fosse aprovado, provavelmente escolheria ficar em Curitiba, uma vez que nesta cidade fui criado e tinha um ambiente familiar e de relações sociais bem estruturado. Reconhecer a importância da reprovação na instituição em que hoje sou professor não visa comparar os programas da PUC-SP e da UFPR na época, vez que desconheço como funcionava o mestrado na UFPR naquele período. O que pretendo ressaltar é que sair de Curitiba, da minha zona de conforto, para viver e estudar em São Paulo, cidade caótica e cosmopolita, mudou completamente a minha maneira de pensar e planejar a vida. Na PUC-SP decidi: quero ser acadêmico, vou cursar mestrado, doutorado, vou prestar todos os concursos possíveis para ingressar na carreira do magistério superior.

Neste espaço, fiz amigos que foram e são importantes na minha trajetória, como Bruno Bontempi, Cecília Cação, Elianda Tiballi, Fernando Casadei, Ivan Russeff, Jorge Carvalho, José de Sousa Miguel Lopes, Kasumi Munakata, Maria Arlete Rosa, Maria Isabel Serrão, Paulo Donadio, Paulo Tumolo, Vera 
Peroni, entre outros colegas da PUC-SP que admiro. Nesse espaço, frequentei cursos e conferências de professores que conhecia apenas pelas leituras, tais como Paulo Freire, Florestan Fernandes, Octavio Ianni, Arthur Gianotti, Peter Burke, François Dosse, José Paulo Neto, entre outros. Os cursos e seminários da Mirian Warde, orientadora für ewig, fiz todos. Nas minhas bancas de mestrado e doutorado contei com a presença de professores ilustres e sábios, entre os quais gostaria de destacar Carlos Nelson Coutinho, autoridade sem contestação nas lides da interpretação do pensamento gramsciano, e Leandro Konder, esse presente tanto na banca de mestrado, como na de doutorado. Desse filósofo guardo um sentimento forte de saudades e de admiração, pois, para além das bancas, convivemos juntos no Rio de Janeiro, no primeiro semestre de 1997, em uma leitura orientada sobre o pensamento de Hegel, que ele ofereceu para mim nas dependências da PUC no Rio. Todas as sextas-feiras começávamos por falar em Hegel na sua sala e terminávamos em um bar da Gávea discutindo os erros do partidão.

Vivendo em São Paulo enquanto cursava as disciplinas do mestrado passei a viver a distância a vida partidária. A campanha de Roberto Freire para a presidência do Brasil em 1989, nas vésperas do meu ingresso no mestrado na PUC-SP, foi o meu último ato de militância partidária. Nos anos seguintes, a cisão do PCB, na maré montante da queda do muro de Berlim e da Perestroika, e a criação, por um grupo majoritário do partido, do ideologicamente descaracterizado Partido Popular Socialista (PPS), foram decisivos para minha orientação para o mundo acadêmico. Caminho sem volta, uma vez que, ainda cursando mestrado, fui aprovado em minha primeira tentativa de concurso, em fevereiro de 1992, para a carreira do magistério superior na UFPR, um mês após a dissolução do tradicional partidão. A UFPR à época tinha como Reitor Carlos Alberto Faraco, amigo que admiro.

Diante dessa análise não é possível dizer que a academia chegou por acaso na minha vida, contudo é notório que não foi o resultado de um plano meditado e executado em cada detalhe. As coisas foram acontecendo, em grande medida, a minha revelia. Conheci pessoas que me ajudaram, outras que me atrapalharam, fiz cálculos, segui intuições, sofri constrangimentos, fiz escolhas pensadas e impensadas e cheguei onde me encontro. Poderia ser diferente, mas aqui não é espaço para especular.

Neste percurso assumi múltiplas identidades, nem sempre compatíveis entre si. Analisando retrospectivamente percebo que determinações do meu meio social e familiar foram decisivas, porém, identifico também a força do acaso, do imponderável, da rebeldia da realidade que faz da trajetória de vida algo imponderável. 


\section{Da experiência acadêmica: os espaços de sociabilidade}

Dentre as muitas atividades acadêmicas na UFPR e em outros espaços externos à instituição posso apenas destacar algumas experiências e reflexões. Não pretendo articulá-las, já que muitas sequer são passíveis de articulação. Optei por selecionar aquelas situadas a partir da conclusão do meu doutoramento em março de 1999, quando defendi a tese Historicismo, cultura e formação humana no pensamento de Antonio Gramsci. A primeira função, assumida nessa fase posterior à conclusão dos estudos pós-graduados, foi a editoria do periódico do Setor de Educação (Educar em Revista), classificado à época como "local e não recomendado" para publicação pela avaliação da CAPES. Em alguns anos de trabalho - rompendo com a forte endogenia que marcava o periódico e, por extensão, captando textos de pesquisadores de renome nacional e internacional, a partir de uma política de dossiês temáticos - chegamos ao conceito Nacional B, à época o penúltimo nível na escala de avaliação da agência supracitada. O Editor que me sucedeu foi o professor Marcus Levy, amigo dileto de tantas jornadas, que levou a Educar à avaliação máxima, na qual o periódico permanece até o presente momento. A linha editorial dos dossiês temáticos, implantada naquela gestão, segue até hoje como diretriz da revista.

Essa vivência me provocou a pensar a centralidade das publicações científicas na dinamização do debate acadêmico, de modo que depois da Educar ainda somei outras experiências. Na Revista Brasileira de História da Educação (RBHE), vinculada à Sociedade Brasileira de História da Educação (SBHE), atuei por dois (2) anos. Aúltima das investidas editoriais foi na Revista Brasileira de Educação, da Anped. Nessa trabalhei seis (6) anos, de 2010 a 2016, sendo que nos últimos três (3) anos ocupei a função de Editor Chefe. Entendo ter dado uma contribuição para a internacionalização desse periódico, além de lá ter feito amigos e amigas muito caros e sempre presentes nas minhas lembranças. Nesses espaços de editoria científica me recordo do trabalho extenuante, mas de poucos reveses, já que sempre contei com o apoio das instituições mantenedoras dos periódicos, seja do Setor de Educação, da SBHE ou da Anped.

Os periódicos vêm assumindo uma função chave, uma vez que são espaços em que a submissão dos textos e arbitragem da avaliação por pares garante um grau maior de qualidade nas publicações. Já no mercado dos livros sabemos que são poucas as editoras que estabelecem algum critério de qualidade acadêmica, prevalecendo o pagamento dos custos editoriais como princípio do que pode ou não ser publicado. Outro aspecto importante dos periódicos é o potencial que eles têm para estabelecer um espaço de comunicação das pesquisas produzidas 
no Brasil com outros países, já que esses estão estabelecidos como canal de comunicação na cultura acadêmica internacional. No contexto brasileiro o que identificamos é um excesso de periódicos na área de educação de baixa qualidade editorial, de modo que gastamos recursos e energias para publicarmos de forma dispersa em periódicos de baixo impacto e circulação restrita, quando deveríamos nos concentrar em um número menor de publicações de alta qualidade editorial e com uma clara política de internacionalização.

No âmbito da organização da pesquisa a minha participação na criação, em 1999, da Linha de Pesquisa de História e Historiografia da Educação, no Programa de Pós-graduação em Educação (PPGE), representa um momento marcante. Fui o primeiro Coordenador da linha que inaugurou, no contexto paranaense, um esforço sistematizado e organizado institucionalmente de pesquisa em história da educação. Juntamente com as professoras Serlei Ranzi, Maria Cecília Marins e o professor Marcus Levy organizamos a linha de pesquisa que segue influente no PPGE e ocupando um lugar reconhecido no cenário nacional. Nesse espaço, como na letra da canção Eduardo e Monica, de Renato Russo, "comemoramos juntos e, também, brigamos juntos muitas vezes depois", mas seguimos unidos em um coletivo que reúne personalidades fortes, projetos de pesquisa inovadores e de abrangência nacional e internacional. Coordenada atualmente pela competente Liane Bertucci, a linha de pesquisa vem se renovando, a partir do credenciamento de novos professores e professoras que foram se incorporando ao longo dos anos, sendo que alguns desses foram doutorandos da linha e passaram a formar um grupo que indica a continuidade do percurso inaugurado em 1999.

No âmbito da linha venho orientando trabalho nas seguintes temáticas: Intelectuais, Ideias e Discursos Educativos; Modernidade e Educação; Imprensa Periódica e Educação; Historiografia da Educação e História Intelectual. Esse trabalho de formação de novos pesquisadores rendeu até o presente, sob a minha orientação, quatorze (14) mestrados e nove (9) doutorados concluídos. Soma-se a essa conta mais de vinte (20) orientações de Iniciação Científica. Dos nove (9) doutores, sete (7) são professores universitários e quatro (4) atuam na pós-graduação stricto sensu. Importante dizer que das atividades que desenvolvo na vida acadêmica a orientação é aquela com a qual mais tenho identificação. O diálogo orientador/orientando é fascinante, pois, por um lado, demanda uma sutileza na condução para não impor demasiadamente as ideias do orientador sobre a pesquisa do orientado. E, por outro, é preciso guiar o trabalho para evitar desperdício de tempo e energia por parte do orientando.

No plano da minha atuação no PPGE destaco, também, a minha passagem como Coordenador do programa, entre os anos de 2000 e 2002, tendo como Vice Coordenador o professor Marcus Levy. Nesse período alcançamos duas 
importantes conquistas: elevamos a nota do programa na avaliação da CAPES de três (3) para cinco (5) e criamos o doutorado (2001). Com a criação do doutorado o PPGE ganhou outro dinamismo, à medida que passou efetivamente a ser um lugar de referência na produção de conhecimento.

A experiência na administração do PPGE foi produtiva, como revelam os resultados da avaliação da CAPES, porém, essa deixou claro para mim que a administração não era a minha "missão" na universidade. Dessa identidade me eximi, de modo que nunca fui Chefe de Departamento, Coordenador de Curso, Diretor ou Vice-Diretor de Setor e jamais ocupei cargos na administração superior da universidade. Não faltaram incentivos ou pressões para isso, mas sempre me esquivei. Essa postura provavelmente provoca alguma indignação entre os meus pares, uma vez que alguém precisa assumir essas funções centrais na vida universitária. Seguindo a mesma lógica, minha presença nas reuniões do Departamento e nas assembleias setoriais é pouco frequente e de participação muito tímida. Isso para não falar da minha completa ausência nas reuniões do sindicato dos professores, seja em tempos de calmaria ou no calor das greves. Como pensar esse comportamento à luz da crença, abraçada nos anos que antecederam ao meu ingresso na UFPR, de que deveria dedicar a minha vida à política e à revolução? Desilusão? Tornei-me alienado, conformista?

Talvez, gosto de pensar assim, à medida que isso ajuda a me justificar, compenso essa ausência na administração direta da universidade e nas decisões colegiadas assumindo com intensidade e comprometimento o ensino na graduação e na pós-graduação, a pesquisa, a formação de novos pesquisadores e a representação da UFPR em fretes externas à instituição. Entre essas posso novamente mencionar o trabalho na editoria de periódicos de alcance nacional e internacional (RBHE e RBE); além da Vice Coordenação e Coordenação, entre 2003 e 2007, do Grupo de Trabalho de História da Educação, da Anped (GT-HE); e as posições de Vice-Presidente e Presidente da Sociedade Brasileira de História da Educação (SBHE), entre 2013-2016. Ocupando essas funções tornei-me Presidente do Comitê Científico da Anped, entre 2004 e 2005, além de organizar três (3) importantes congressos nacionais e internacionais: O VII Congresso luso-brasileiro de história da educação (2008) e os VIII e IX Congressos brasileiros de história da educação (2015 e 2017). Nestes anos no GT-HE e na SBHE trabalhei diretamente com José Gonçalves Gondra, amigo precioso.

A gestão acadêmica no contexto nacional é, sem dúvida, menos onerosa em termos de desgastes nas relações pessoais, pois os conflitos inevitáveis nesses espaços são mais fáceis de serem contornados, se comparamos com aqueles que vivemos nas nossas próprias instituições, onde o contato pessoal é quase que diário. Essa frequência no contato, pelo menos na minha percepção, favorece que o conflito de ideias evolua às raias da inimizade. Acresça-se a isso, evidentemente, 
que a ocupação de cargos na administração expõe mais as pessoas a contrair esses desafetos. Da minha parte, dou-me por satisfeito pelo reduzido número de desafetos que contraí, além do que, na maioria dos casos, o tempo e as mudanças nas configurações institucionais têm contribuído para que antigas desavenças sejam superadas. Com a maturidade e a experiência na instituição e no campo acadêmico de forma geral, fui sendo capaz de imprimir o lema da famosa canção dos Titãs, Go Back: "Só quero saber do que pode dar certo, não tenho tempo a perder".

Um outro momento que destaco na minha trajetória na UFPR foi a organização do Grupo de Pesquisa História Intelectual e Educação (GPHIE). Fundado em 2006 e sob a minha coordenação, o GPHIE completou em 2016 dez (10) anos de trabalho ininterrupto, com reuniões mensais. O GPHIE tem como Vice Coordenadora a professora Dulce Regina Baggio Osinski, ex-orientada, professora do PPGE e amiga de todas as horas. Nascido para organizar o meu trabalho como orientador na pós-graduação, hoje o grupo ultrapassa em muito essa função, uma vez que conta com dezesseis (16) doutores entre os seus mais de trinta (30) membros. A sua composição é interdisciplinar, considerando a diversidade de formações dos seus membros, tendo em comum a história da educação como tema de pesquisa. Seus pesquisadores atuam no ensino universitário de várias instituições e na rede pública de Ensino Fundamental e Médio, participando em programas de iniciação científica, especialização, mestrado e doutorado, seja na condição de docentes ou de discentes. O GPHIE tem como escopo investigar historicamente a prática social dos intelectuais, particularmente daqueles que se engajaram direta e intensamente na difusão do discurso sobre a relação entre educação e modernidade. Em termos metodológicos, o grupo pretende problematizar o discurso educacional, a partir dos seus contextos de produção, circulação e recepção. Esse modo de pensar visa contribuir para a escrita de uma história da educação articulada à história das linguagens, das práticas políticas, das profissões ligadas à esfera cultural, das formas de transmissão da cultura e dos meios e dos lugares de construção do conhecimento.

No âmbito do ensino na graduação, cumpre confessar que não me dediquei seriamente a pesquisar métodos inovadores de ensino. Contudo, atento ao debate sobre o ensino de história, tenho buscado sempre inovar o meu programa, evitando formas anacrônicas de ensino da história e da história da educação. Antes de ensinar história, busco problematizar o como se escreve a história e a razão de estudá-la. Ensinar na graduação não é a minha motivação principal na vida acadêmica, mas não encaro essa atividade como um flagelo, ao contrário, entendo-a como importante e me sinto bem em realizá-la.

A respeito do ensino de graduação, a questão que gostaria de problematizar está relacionada ao lugar ocupado pela disciplina História da Educação no curso de Pedagogia, onde atuo preferencialmente. Em estudo que realizei e publiquei 
em 2016, intitulado História da Disciplina História da Educação no curso de Pedagogia da UFPR (1939-2014), argumento que a representação da disciplina História da Educação como Magistra Vitae, que marcou a sua emergência nos cursos de formação de professores normalistas e que acompanhou o seu desenvolvimento nos cursos de Pedagogia, cedeu lugar para outra forma de conceber a disciplina, alterando a sua identidade no interior do curso de graduação. A nova concepção, presente nas instituições em que a história da educação é também um campo de pesquisa, é a da história como espaço de reflexão sobre as experiências formativas do passado, interpretando-as nas suas especificidades contextuais, evitando as generalizações e as comparações que, em regra, redundam em manipulações presentistas e interpretações anacrônicas do passado.

Nessa abordagem, com a qual me identifico, a compreensão do passado possibilita a desnaturalização do mundo social, mostrando como os processos formativos foram resultantes de escolhas, entre outras possíveis, de indivíduos e de grupos sociais, ora em confronto, ora em colaboração, e em posições de poder diferenciadas. Essa maneira de pensar a história da educação e o seu papel na formação de professores e de pedagogos não tem sido incorporada sem tensões. Por um lado, permanece uma expectativa do curso de Pedagogia e, sobretudo, dos seus estudantes de buscar no passado lições ou aplicações para os tempos presentes. E, por outro, a especialização dos professores de História da Educação como pesquisadores de uma especialidade da história, leva-os a procurar interlocuções na história ou na comunidade dos historiadores da educação, produzindo certo distanciamento desses em relação às questões educacionais em debate no tempo presente, particularmente sobre a formação de pedagogos.

Neste estudo identifiquei a tendência - a partir das reformas curriculares do curso de Pedagogia na UFPR, nos anos de 1985, 1996 e 2008 - de diminuição da carga horária da História da Educação na graduação, em contraste com o período entre os anos de 1939 e 1980, em que a disciplina ocupava um lugar central no currículo, a par e passo com a Psicologia da Educação. Outro índice nessa mesma direção é a presença inexpressiva de Trabalhos de Conclusão de Curso (TCCs), apresentados por alunos de Pedagogia, abordando temas históricos nas suas pesquisas. Analisando os cento e vinte e cinco TCCs defendidos pelos alunos de graduação em Pedagogia, entre 2013 e 2014, apenas três apresentavam problemas de caráter histórico. Em outros termos, 2,4\% dos alunos formandos se interessaram em produzir os seus TCCs relacionados à história da educação.

Diante desse quadro, que combina o vigor da área de pesquisa e a tendência de limitação da disciplina no âmbito da graduação em Pedagogia, algumas questões se apresentam: a especialização da história da educação como especialidade da história terá como resultante o seu completo afastamento da Pedagogia? Ou ainda: a história da educação pode se desenvolver como área de 
pesquisa acadêmica, sem perder a sua identidade como disciplina formadora de pedagogos? A tendência à especialização da educação nos termos postos pelas tecnologias e pelas técnicas de ensino terá como consequência a redução ou a extinção das humanidades nos cursos de formação de professores? Bem, não tenho a pretensão de responder essas questões neste momento, contudo, acredito que elas são fundamentais para pensarmos o futuro da História da Educação no curso de Pedagogia e nas licenciaturas.

Um dado novo e alentador no ensino de graduação será a oferta, a partir de 2017, de uma disciplina de História da Educação no Brasil, no ciclo comum do Bacharelado e da Licenciatura em História, atendendo a demanda do Departamento de História. É certo que essa solicitação só ocorreu em função do reconhecimento do trabalho dos professores da área de História da Educação, a partir de bancas, publicações conjuntas, atividades de pesquisa e intercâmbio de alunos que temos realizado com os professores do Departamento de História.

Para concluir esta parte da minha autoanálise em relação à experiência institucional e às redes de sociabilidade, quero me manifestar sobre aquilo que considero a mais atraente das condições oferecidas pela carreira, ou seja, a possibilidade de formação e de intercâmbio. Realizei o meu doutorado na PUC-SP com bolsa de estudos e afastamento das minhas atividades laborais. Foram quatro (4) anos (1995-1998), sendo que no terceiro ano, aproveitando uma oportunidade oferecida pelo programa da PUC-SP, viajei para Florença (Itália) e lá fiquei por nove (9) meses estudando na Università Degli Studi di Firenze. Esse período não foi fundamental apenas para o estudo do pensamento gramsciano, meu objeto na tese, pois, para além do que pesquisei, conheci diretamente a cultura e a língua italiana e a cultura universitária europeia. Anos mais tarde, em 2008 para ser mais preciso, fui à Universidade de Cambridge na Inglaterra e lá permaneci por um (1) ano, estudando em uma renomada universidade, como membro do grupo de pesquisa de um dos mais conhecidos e controvertidos historiadores do pensamento político e da história intelectual, Quentin Skinner. Em 2009, retornei à Inglaterra por mais três (3) meses, agora em Londres, no seu Instituto de Educação, com uma bolsa do Consulado Britânico. Em 2015, outra viagem, agora para a Universidade de Stanford nos EUA, também um (1) ano, período em que acompanhei os debates do Philosophical Reading Group, coordenado pelo Professor Hans Gumbrecht. Nesse espaço, convivi com intelectuais de percepção sofisticada, entre os quais destaco o amigo Leopoldo Waizbort. Entremeando esses estágios no exterior aconteceram incontáveis viagens para bancas e congressos nacionais e internacionais.

Tudo isso aconteceu recebendo meu salário e tendo a certeza que no meu retorno o meu emprego estava garantido. Essa é uma condição profissional que pouquíssimas carreiras oferecem. Não acho que isso seja um privilégio, ao passo 
que, sem isso, qualquer pretensão de desenvolvimento científico consistente fica comprometido. Contudo, não posso deixar de mencionar o suporte que recebi para me tornar o que sou na carreira acadêmica, considerando tanto o apoio da UFPR, da PUC-SP, como das agências de fomento CAPES e CNPq. Dessa última também tenho recebido financiamento regular desde 2002, quando ingressei na carreira de Pesquisador Produtividade. O investimento no cientista, na pesquisa e no intercâmbio internacional tem se revelado como excelente política de Estado no Brasil. Todavia, os tempos recentes não ensejam otimismo. Talvez, considerando os tramites da Proposta de Emenda Constitucional $241 \mathrm{e}$ os últimos movimentos do Estado brasileiro em relação às políticas de Ciência e Tecnologia, as novas gerações de pesquisadores não venham a encontrar as mesmas possibilidades que aproveitei neste meu processo de formação e de inserção no mundo acadêmico internacional.

O saldo dessa experiência não pode ser medido apenas pelo contato com as instituições estrangeiras, pelos produtos gerados (publicações, projetos, etc.), uma vez que a viagem em si, como já afirmava Michel de Montaigne (1972), no século XVI, é um aprendizado que revoluciona o modo do sujeito pensar e agir no mundo. Para além daquilo que usufruí, minhas amadas esposa Raquel e filha Roberta foram profundamente impactadas por esse convívio com outras culturas, línguas e comportamentos. Da minha parte, tudo que aprendi nessas andanças tentei disseminar, a partir das minhas publicações e intervenções na esfera acadêmica no Brasil. Assim, as apropriações que fiz de Gramsci, do contextualismo linguístico e da história dos conceitos, em Florença, Cambridge e Stanford respectivamente, ganharam circulação entre meus alunos e leitores, de modo que, acredito, tenham produzido algum impacto na história da educação, tanto na esfera local, como nacional.

\section{Da pesquisa: problemas e métodos}

Nesta última parte deste memorial, lacunar e sem qualquer presunção de cobrir a totalidade da minha experiência acadêmica, optei por percorrer alguns momentos das minhas reflexões associadas à teoria da história. Farei aquilo que Rego (2014), citada na introdução, chamou de exercício metateórico, ou seja, uma reflexão abrangente sobre as interlocuções teóricas realizadas com o objetivo de produção de conhecimento histórico. Abdico, portanto, de fazer um balanço dos resultados do conhecimento histórico sobre os intelectuais e o discurso educacional que venho produzindo, contudo, aos interessados, esse 
conhecimento está disponível nos 25 artigos e nos 22 livros e capítulos que publiquei até o presente momento.

Como já mencionei, os meus estudos pós-graduados na PUC-SP foram decisivos para minha formação. Dos escritos de mestrado e doutorado sobre Gramsci extraí três orientações que me acompanham. A primeira está associada à compreensão da teoria de Gramsci e da sua potencialidade para interpretar as relações de poder, assim como o lugar da cultura, dos intelectuais e dos processos formativos, em contexto de conflitos entre os diferentes grupos sociais que têm pretensões hegemônicas. A segunda se inscreve na teoria do conhecimento historicista sustentada por Gramsci, manifesta de forma sintética na frase enigmática, presente nos seus escritos e que reverberou nas minhas meditações por longo tempo: o marxismo é um "historicismo absoluto, a mundanalidade e terrenalidade absoluta do pensamento, um humanismo absoluto da história" (GRAMSCI, 1977, p. 1437). Concluí, depois de muita pesquisa e reflexão, que o marxismo para Gramsci é um historicismo absoluto na medida em que essa teoria

[...] supõe que não existe nada para além da história, nada que determine o seu sentido que não esteja contido na própria realidade. O marxismo é historicismo ou humanismo absoluto, pois, se não existe nada para além da história, na história não existe nada para além das práticas humanas e das suas consequências culturais. (VIEIRA, 1999, p. 122).

A apropriação dessa ideia me colocou definitivamente no contexto dos estudos históricos, de modo que a identidade de filósofo que persegui por algum tempo, cedeu para a representação do historiador, especificamente daquele que pesquisa a história da educação e a história intelectual.

O terceiro aspecto está associado ao contexto da conclusão do meu doutorado e, sobretudo, do meu credenciamento no PPGE, na Linha de História e Historiografia. A questão que se impôs era: concluído o doutorado, que problemas históricos me interessariam estudar e com que método os abordaria? Diante do problema decidi que não me dedicaria mais a estudar Gramsci e as suas ideias como foco principal nas minhas pesquisas. Duas razões me levaram a isso. A primeira porque precisava de uma questão ampla o suficiente para acolher a minha pesquisa e a dos meus futuros orientandos. A segunda razão é porque já estava se consolidando entre as pessoas do meu convívio acadêmico a representação do "Carlos Eduardo do Gramsci". Em outras palavras, o meu objeto de estudos pós-graduados começava a se tornar parte da minha identidade social e acadêmica. Trata-se daquele fenômeno, citado anteriormente, da identificação e 
da transferência entre autor e personagem. Na filosofia isso é comum, ou seja, filósofos dedicam suas vidas ao estudo de um pensador célebre e produzem a sua identidade acadêmica nessa interseção entre intérprete e interpretado. Não obstante, na história isso não é comum e, assim, essa identificação não me ajudaria a conduzir minha carreira, pelo contrário, reforçaria desconfiança da falta de identidade disciplinar dos meus projetos.

O caminho percorrido, com um bom grau de consciência, foi seguir com os problemas postos pelos estudos de Gramsci, ou seja, a função social dos intelectuais e a historicidade das ideias. No meu caso e dos meus orientados, o foco recaiu sobre os intelectuais vinculados ao debate educacional no Paraná e no Brasil e as teses, projetos e reformas educacionais por esses defendidas e promovidas. $\mathrm{O}$ grande problema da escolha desse caminho é que ele, em alguma medida, estava na contracorrente das tendências em curso na área de história da educação. A história das ideias e as suas variantes na história da educação e da pedagogia, ao longo dos anos de 1990 no Brasil e no exterior, foram veementemente criticadas, a partir da caracterização desse gênero como filosófico e, por extensão, anistórico.

Essa crítica ficou celebrizada, na expressão de Lucien Febvre (1989), como história desencarnada das ideias. A replicação desta crítica, que desqualificava a história da filosofia e das ideias como modelo para a escrita da história da educação, produziu uma espécie de truísmo no interior campo ${ }^{3}$. Sendo assim, a questão que se colocava para a continuidade do meu projeto como pesquisador e professor na pós-graduação era a seguinte: a consagração da crítica ao modo filosófico de narrar a história da educação, significava, também, renunciar definitivamente à abordagem histórica das ideias e das teorias pedagógicas? Parte dos pesquisadores do campo de pesquisa entendeu que sim, eram necessários novos objetos, novas fontes e, sobretudo, novas formas de pensar a história da educação. Esse movimento, a meu ver, extremamente rico e positivo, passou a explorar conceitos e problemas como cultura escolar, práticas, representações, memórias, leitura e escrita, cultura material, espaço e tempo escolar. Nesse enquadramento da questão acima formulada, a história das ideias seria sempre um gênero filosófico que não se aproxima dos estudos históricos.

Porém, na minha perspectiva e seguramente de outros pesquisadores, era possível responder à questão acima formulada de forma diversa, qual seja: é possível manter na pauta historiográfica os estudos sobre o pensamento e as teorias educacionais, contudo, será necessária uma revisão profunda dos métodos aplicados nesse tipo de investigação. É nesse contexto que três tradições

3 No que tange à estruturação dessa crítica no contexto da história da educação ver, entre outros: A História da Educação no Brasil, de Marta Carvalho; Questões teóricas e de Método: a História da Educação nos marcos de uma disciplina, de Mirian Warde. 
historiográficas, paulatinamente, passaram a fazer parte das minhas reflexões: a história dos intelectuais, a história intelectual e a história dos conceitos.

A história dos intelectuais tem na França e na Itália grande desenvolvimento, e liga-se intimamente à história política. No contexto francês, a teoria de Bourdieu é bastante mobilizada para esse tipo de análise, enquanto que no contexto italiano, Gramsci é uma referência consagrada. Já a história intelectual é parte de um movimento mais recente e, portanto, difícil de ser definido, tanto em termos de presença nas diferentes culturas historiográficas nacionais, como em termos de métodos e de objetos compartilhados. Sob a denominação de história intelectual identificamos uma multiplicidade de possibilidades, envolvendo, tanto os estudos dos pensadores clássicos da política, da filosofia ou da ciência, como as formas de pensamento ou representações sociais produzidas por homens ou mulheres que viveram às margens do mundo intelectual e/ou editorial ${ }^{4}$. A história dos conceitos tem sua marca distintiva na tradição hermenêutica germânica, tendo Koselleck como uma das suas expressões maiores. O ponto em comum dessas tradições é a oposição às ideias desencarnadas, de maneira que, tanto a história dos intelectuais como a história intelectual e dos conceitos se revelaram atraentes para aqueles interessados em seguir explorando historicamente a esfera cultural, nas suas dimensões de produção, circulação e recepção de ideias e de crenças em contextos históricos determinados.

Nesses termos, nos anos 2000, assumi a produção de pesquisas e a orientação de estudos na Linha de Pesquisa de História e Historiografia, a partir do eixo temático: Intelectuais e ideias educativas. Esse projeto visava, a um só tempo, recusar a tradição da história filosófica da educação, mas insistia no estudo histórico do pensamento, das ideias e do discurso pedagógico. Gramsci seguiu entre as inspirações metodológicas, mas ao longo do tempo outros teóricos se somaram, entre os quais destacamos Bourdieu, Skinner, Pocock e Koselleck.

Com Bourdieu aprendi a pensar as determinações, os constrangimentos que permitem perceber os intelectuais e as suas ideias em contextos estruturados e estruturantes, a partir de escalas mais bem dimensionadas pelos conceitos de campo, habitus e capital. Nesse cenário, o diálogo com o pensamento de Bourdieu permitiu explicar ideias e comportamentos assumidos como decisões autônomas, originais e singulares, pelos próprios intelectuais investigados e reforçados pelos seus hagiógrafos, como parte de uma lógica de determinações estruturais, produzida em espaços profissionais, religiosos, políticos ou familiares. O diálogo com essas noções possibilitou um refinamento na apreensão da

4 Um exemplo de estudo instigante sobre a formação intelectual de estratos sociais subalternos na Idade Média, ver O mendigo e o professor: a saga da família Platter no século XVI, de Emmanuel Le Roy Ladurie. 
relação entre indivíduo e sociedade, evitando tanto a representação da completa liberdade de escolha dos indivíduos, como a percepção inversa da impotência desses perante os condicionamentos estruturais. Prevaleceu a noção, compartilhada com Marcus Taborda de Oliveira, de que

[...] a história deve ser concebida estruturalmente, desde que entendamos as chamadas estruturas sociais como espaços de sociabilidade, nos quais os indivíduos e os grupos sociais se movimentam, lutam pelos seus projetos e criam uma dinâmica social e histórica própria e, em grande medida, rebelde às teorias sociais disponíveis. (VIEIRA; OLIVEIRA, 2010, p. 528).

O diálogo com a história intelectual, particularmente com as obras de Skinner e Pocock, aconteceu ainda no meu doutorado, contudo, intensificou-se nos anos seguintes até a minha estada na Universidade de Cambridge. O contextualismo linguístico, como prefiro denominar essa teoria, ofereceu para meus intentos de pesquisa métodos capazes de ensejar a apreensão das ideias nos seus contextos de enunciação, de forma a produzir estudos eminentemente históricos; buscando estabelecer os liames entre o plano subjetivo dos sentidos (ideias e discursos) e o plano objetivo das práticas sociais.

A grande contribuição do contextualismo para os meus trabalhos tem sido, por um lado, a possibilidade que os seus métodos fornecem para os processos de interpretação de fontes documentais, na medida em que as suas teorias estão solidamente apoiadas nos estudos sobre o funcionamento da linguagem ordinária. Por outro, propicia estudos que não estão necessariamente focados sobre trajetórias de intelectuais, mas sim em movimentos culturais mais amplos, situados nos planos da enunciação e da circulação de discursos formativos. O contextualismo tem sido uma opção para pensar a estruturação (morfologia), o funcionamento (retórica) e, sobretudo, os usos sociais do discurso educativo (pragmática). Algumas orientações gerais do contextualismo foram amplamente incorporadas em minhas pesquisas, tais como: a necessidade de acessarmos as crenças e os conceitos normativos que regem os processos de enunciação da intelligentsia engajada na produção do discurso educacional, considerando, a partir da noção de L. Wittgenstein apropriada pelo contextualismo, os jogos de linguagem nos quais esses são protagonistas; bem como o axioma, repetido inúmeras vezes por Skinner, de que o entendimento histórico do discurso, seja ele político ou educacional, supõe a compreensão do projeto político ou intelectual ao qual o agente da enunciação estava vinculado. Trata-se da questão da força ilocucionária, noção desenvolvida por J. Austin e apropriada pelo contextualismo, que supõe a apreensão da intencionalidade do autor nos seus atos de comunicação. 
O diálogo que se estabeleceu de forma mais recente na minha produção foi com a história dos conceitos, interesse que me levou à Universidade de Stanford para trabalhar junto com Hans Gumbrecht. Despertei para o estudo dessa proposição metodológica no período em Cambridge, uma vez que lá muito foi falado, nos seminários semanais no Kings College, sobre a disputa dessa teoria com o contextualismo no cenário da história intelectual. Nas minhas leituras dessa teoria, aquilo que era apresentado como disputa, foi se revelando como uma outra possibilidade de pesquisa, considerando que, se o contextualismo visa entender o funcionamento dos jogos de linguagem e o comportamento linguístico de seus participantes, a história dos conceitos privilegia a recepção dos conceitos. Esses são considerados em perspectiva histórica, na média e na longa duração, a partir da análise da variação semântica inerente aos processos de apropriação e ressignificação dos termos. Em uma chave de leitura pragmática, tanto uma perspectiva, como a outra, podem ser úteis, a depender dos problemas que formularmos.

Esse rol amplo de possibilidades teóricas com as quais tenho dialogado não deve ser interpretado como ecletismo, mas sim com uma postura plural $\mathrm{e}$ "herética", já que nunca me fidelizei a nenhuma teoria social ou científica. O lema é dialogar com distintas proposições teóricas para resolver problemas presentes em corpus documentais de natureza diferentes. Dessa maneira, as ideias, conceitos e procedimentos presentes na história dos intelectuais, intelectual e dos conceitos, podem ser identificados e entendidos na minha produção e de meus orientados no campo da história da educação.

\section{REFERÊNCIAS}

ALTHUSSER, L. O futuro dura muito tempo. São Paulo: Companhia das Letras, 1992. BOURDIEU, P. Esboço de autoanálise. São Paulo: Companhia das Letras, 2005.

BOURDIEU, P. A ilusão biográfica. In: FERREIRA, M. M.; AMADO J. (Org.). Usos e abusos da História Oral. Rio de Janeiro: FGV, 2006. p. 183-192.

CARVALHO, M. M. C. de. A História da Educação no Brasil. In: CARVALHO, M. M. C. de. A escola e a república e outros ensaios. Bragança Paulista: EDUSF, 2003. p. 281-312.

DOSSE, F. O desafio biográfico: escrever uma vida. São Paulo: Edusp, 2009.

FEBVRE, L. Combates pela história. 3. ed. Lisboa: Presença, 1989.

GRAMSCI, A. Quaderni del carcere. Torino: Einaudi, 1977.

LADURIE, E. L. R. O mendigo e o professor: a saga da familia Platter no século XVI. 
Rio de Janeiro: Rocco, 1999.

LORIGA, S. A biografia como problema. In: REVEL, J. (Org.). Jogos de escalas. A experiência da microanálise. Rio de Janeiro: Editora da Fundação Getúlio Vargas, 1998.

MONTAIGNE, M. Da educação das crianças. In: MONTAIGNE, M. Ensaios. São Paulo: Abril Cultural, 1972. p. 79-93.

POCOCK, J. G. A. O conceito de linguagem e o métier d'historien: algumas considerações sobre a prática. In: POCOCK, J. G. A. Linguagens do ideário político. São Paulo: EDUSP, 2003.

REGO, T. C. Trajetória intelectual de pesquisadores da educação a fecundidade do estudo dos memoriais acadêmicos. Revista Brasileira de Educação, v. 19, nº 58. jul.-set. 2014. Disponível em: <http://www.scielo.br/pdf/rbedu/v19n58/13.pdf>. Acesso em: 04 nov. 2015.

RICOEUR, P. Memória, a história, o esquecimento.Campinas: UNICAMP, 2007.

SKINNER, Q. Meaning and understanding in the History of Ideas. In: SKINNER, Q. Visions of politics: regarding method. Cambridge: Cambridge University Press, 2002. 1v.

VIEIRA, C. E. Historicismo, cultura e formação humana no pensamento de Antonio Gramsci. São Paulo, 1999. Tese (Doutorado em História e Filosofia da Educação) Pontifícia Universidade Católica de São Paulo.

VIEIRA, C. E. Intelectuais, educação e modernidade no Paraná (1886-1964). Curitiba: UFPR, 2007.

VIEIRA, C. E. História da Educação e História da Filosofia: culturas cruzadas a partir das concepções de história e de escrita da história em Hegel. Proposições, Campinas, v. 20, no 1, p. 189-206, 2009.

VIEIRA, C. E. ; OLIVEIRA, M. A. T. Thompson e Gramsci: História, Política e Processos de Formação. Educação e Sociedade, Campinas, v. 31, nº 111, p. 519-537, abr.-jun. 2010.

VIEIRA, C. E.; OSINSKI, D. R. B.; STRANG, B. L. S. (Orgs.). História Intelectual e Educação: Trajetórias, Impressos e Eventos. 1. ed. Jundiaí: Paco Editorial, 2015.

VIEIRA, C. E.; GONÇALVES, N. G. (Org.). Setor de Educação e Curso de Pedagogia na Universidade Federal do Paraná (1938-2014): histórias, memórias e desafios contemporâneos. Curitiba: UFPR, 2016.

WARDE, M. J. Questões teóricas e de método: a História da Educação nos marcos de uma história das disciplinas. In: SAVIANI, D.; LOMBARDI, J. C.; ANFELICE, J. L. (Orgs.). História e história da educação. 2. ed. Campinas: Autores Associados, 2000.

Texto recebido em 02 de dezembro de 2016.

Texto aprovado em 21 de dezembro de 2016. 